\title{
Lutero, intérprete de la doctrina de S. Agustín sobre el pecado original
}

\section{Lutero y San Agustín.}

Es bien conocida la frase de los primeros reformadores en sus polémicas con los teólogos católicos: "Si tibi non placet, dic Augustino". $\mathrm{Y}$ es que el monje agustino Martín Lutero, padre de la Reforma, que ya en su profesión religiosa había tomado el nombre de Agustín, adoptó desde un principio como programa de su vida la fidelidad a San Pablo y a San Agustín, según él, el intérprete más fiel del Apóstol. Así lo afirma expresamente en la Controversia de Heidelberg (1518) con ocasión del capítulo provincial convocado por su amigo y superior Staupitz. A las 40 tesis, redactadas por Lutero y defendidas públicamente por el joven agustino Leonhard Beier, les antepuso este prólogo significativo, a guisa de programa perenne: "Teniendo una total desconfianza de nosotros mismos, según el consejo del espíritu: No te apoyes en tu sabiduría... (Prov. 3, 5), ofrecemos humildemente al juicio de todos los que deseen asistir las siguientes paradojas teológicas, para que se vea claramente si han sido sacadas con razón, o no, del divino Pablo, vaso y órgano de Cristo elegido entre nosotros, así como de San Agustín, su intérprete más fiel" 1 .

Ya en una carta del 19 de octubre de 1516 a su amigo Spalatín, no dudaba en afirmar: "Mi disconformidad con Erasmo, no lo dudo, viene de esto: cuando se trata de interpretar las Escrituras, yo prefiero Agustín a Jerónimo en la misma medida en que él, Erasmo, prefiere Jerónimo a Agustín" ". Algunos años más tarde, en 1525, al defender contra el mismo Erasmo sus tesis fundamentales de la "sola fides", contra la existencia del libre albedrío en el orden religioso y contra el valor meri-

1 M. Luther, Oeuvres, “Labor et Fides", I (Genève 1957), 124. Cfr. Ed. Weimar, I, 350-365.

2 Ib., V (Genève 1958), 7; W., I, 70. 
torio de las buenas obras, proclama sin ambages que el humanista holandés omite a San Agustín, el cual está completamente de parte suya: "Augustinus, quem praeteris, meus totus est" ${ }^{3}$. Algunos autores han notado que hacia el 153 I Lutero adopta una postura de reserva con respecto a ciertos puntos de la doctrina agustiniana, como el libre albedrío y la justificación. Ya no encuentra en Agustín tan claramente esa pasividad total del hombre ante su justificación y salvación, ni esta justificación forense o extrínseca, que están a la base de su propia doctrina. En una carta de su discípulo Melanchtón a Brenz, reformador de la Suabia, fechada en mayo de 153I, y que parece expresamente aprobada por alguna palabra de Lutero, podemos leer esta confesión un tanto ambigua: "Tú te has aferrado a las imaginaciones de Agustín, el cual negó que la justicia de la razón sea reputada como justicia ante Dios; y en esto tiene razón. Pero seguidamente se imagina que nosotros somos reputados justos por razón del cumplimiento de la ley que el Espíritu Santo obra en nosotros... Agustín no está en acuerdo perfecto con la doctrina de San Pablo, aunque se le aproxima mucho más que los Escolásticos. I, por mi parte, yo cito a Agustín como enteramente de acuerdo con nosotros, por causa de la persusión del público a este respecto, aunque él no explica suficientemente la justicia por la fe". Y le da el consejo de que "animum revocandum esse ab Augustini imaginatione" ${ }^{4}$. Claro que, más tarde, ni el mismo Melanchtón fue en esto del todo fiel a Lutero; porque, en las obras de su madurez, llega a defender decididamente la libertad humana y la libre cooperación del hombre en la obra de su justificación, si bien quedan en él algunos puntos oscuros, como la armonización entre el empecatamiento humano y la libre cooperación con la gracia divina (Examen Ordinandorum, a. 1559; Corpus Reformatorum, t. 23, p. 15; t. 9, p. 468). L. Cristiani afirma que esta postura un tanto ambigua de Lutero y Melanchtón perdura en los teólogos luteranos hasta el sínodo de Stettin en 1577, al percatarse de que la invocación de San Agustín en favor del luteranismo daba a los teólogos católicos un arma formidable contra ellos ${ }^{5}$.

3 De servo arbitrio (1525): Oeuvres, V, 57; W., 18, 640.

4 Cfr. L. Cristiani, "Luither et saint Augustin": Augustinus Magister, Paris 1954, II, 1.029-1.038; ver pp. 1.037-38; B. LoHse, "Die Bedeutung Augustins für den jungen Luther": Kerygma und Dogma 11 (1965) 116-135; J. LoRTz, S. J., Historia de la Reforma, Madrid 1963, I, 186 ss.; P. Bergauer, Der Jakobusbrief bei Augustinus, Wien 1962, 88 ss.

b L. Cristiani, a. c., 1.038. 
No negamos fundamentalmente estas reservas algo tardías de Lutero con respecto a algunos aspectos de la doctrina agustiniana, por otra parte admitidas también por el mismo Calvino, cuando afirma: "No debemos recibir por entero la tesis de San Agustín; al menos, su modo de hablar no es apropiado. Pues, aunque despoja muy bien al hombre de toda alabanza de justicia propia y la atribuye por entero a Dios, sin embargo refiere la gracia a la santificación por la que somos regenerados en novedad de vida" ${ }^{6}$. Con todo, aun tomando con ciertas reservas las innumerables citas agustinianas aducidas por Lutero después del I53I, como en sus célebres In I Librum Mose Enarrationes (Vorlesungen über I Moses) y en las últimas tesis públicas dirigidas por él en la universidad de Wittenberg, no debemos olvidar que las tesis fundamentales de Lutero nacieron mucho antes, en su opinión, cual fruto auténtico de la doctrina del Apóstol y de su intérprete más fiel, San Agustín. De hecho, los puntos fundamentales de la doctrina de Lutero sobre el pecado original y la concupiscencia (su pecaminosidad perenne en esta vida, su transmisión por generación y sus efectos en la misma naturaleza humana) van corroboradas con abundantes citas agustinianas hasta el fin de su vida. Por eso, consideramos de gran importancia teológica y ecuménica la interpretación que dio Lutero a la doctrina de San Agustín sobre el pecado original y el por qué de la misma.

Nos sorprende ver cómo algunos historiadores católicos de la categoría de un Joseph Lortz, S. J., consideran esa interpretación luterana como una cosa lógica, dada la doctrina del Hiponense, especialmente en sus obras antipelagianas: "En la negación del pensar raciocinante le presta ayuda decisiva San Agustín, que, por otra parte, desempeña un papel decisivo en la interpretación y repercusión del forcejeo de Lutero en torno a la libertad del pecado, justificación, libertad y pecado original... Por otra parte, San Agustín acentuó con extraordinaria energía la impotencia de la voluntad y la realidad del pecado, del pecado que afecta también a los justos. En ciertas formulaciones al fin de su vida aparecen finalmente estas ideas junto con el pensamiento de la libre predestinación del hombre por Dios con tanta exageración que Lutero pudo deducir de ellas que San Agustín aceptaba que la voluntad del hombre estaba radicalmente corrompida y padecía un continuo pecado original : $j$ exac- 
tamente lo que exigía y demostraba la experiencia anímica de Lutero, según su opinión" ?. Es éste un grave error de perspectiva, que adultera radicalmente la doctrina de San Agustín y pasa injustamente por alto la gran confusión teológica de la Edad Media y de las primeras décadas del siglo $\mathrm{xvI}$, debida sobre todo al nominalismo antiescolástico - por una parte neopelagiano o naturalista y por otra parte de tipo agnóstico--, así como al método imperfecto y rudimentario tanto en la exégesis bíblica como en la interpretación de la teología patrística. Y es que todos usaban las categorías aristotélico-tomistas, incluso el mismo Lutero, que tanto se mofaba de ellas como por sistema. El llama a Aristóteles "chivo", "peste", y al glosar a su estilo el Apocalipsis (9, I) no duda en afirmar que Alejandro de Hales, o mejor Santo Tomás es la estrella caída del cielo que aprobó y propagó la filosofía racionalista aristotélica, ruina de la cristiandad ${ }^{8}$. Sin embargo, en la mayor parte de las cuestiones, especialmente en las trinitario-cristológicas, Lutero usa esa misma terminología durante toda su vida. Y ésta es una de las razones decisivas que impidieron tanto a Lutero como a los teólogos católicos interpretar rectamente la doctrina de San Agustín, plasmada en categorías neoplatónicas y bíblicas, según veremos a continuación.

\section{Concepto de "peccatum originale" en los escritos antipelagia- NOS DE SAN Agustín: interpretación DE LOS escolásticos Y DE LuTERo.}

Ya en el De moribus Ecclesiae catholicae (388-39o) nos dice San Agustín que el pecado original es la cosa más conocida para la predicación, pero la más misteriosa para su intelección ${ }^{9}$. Las circunstancias histórico-doctrinales de su tiempo, primero por causa de los maniqueos y sobre todo a partir del $4 \mathrm{I} 2$ por causa de los pelagianos, le obligaron a ocuparse del pecado original con tanta insistencia y amplitud, que resulta de todo punto imposible atender en un breve estudio a todos los aspectos del mismo por él desarrollados. Por eso, aquí tendremos que limitarnos a los puntos fundamentales de su doctrina y a la interpretación que les han dado los teólogos posteriores, especialmente Lutero.

7 J. LoRTz, Historia de la Reforma, I, 186-187.

8 Ad librum eximii Magistri Nostri Magistri Ambrosii Catharini, defensoris Silvestri Prieratis acerrimi, responsio (1521), W., 7, 698 ss.; ver p. 736. 9 "...quo nihil est ad praedicandum notius, nihil ad intelligendum secretius" (De mor. Eccl. cathol, 22, 40, PL, 32, 1.328). 
- I. San Agustín y San Pablo.-No creemos necesario insistir en que San Agustín, al igual que San Pablo, y todos los Santos Padres así como toda la teología cristiana hasta el siglo xix consideran los primeros capítulos del Génesis como un relato histórico que explica el origen del pecado y por ende la presencia del mal en el mundo, como una secuela del orgullo y de la desobediencia de los primeros padres al mandato divino. Ese pecado, libre en Adán, se transmite por generación a todos sus descendientes, convertido así en un "pecado de la naturaleza humana" (peccatum naturae). Lutero se apoyará en San Agustín para defender esta doctrina fundamental hasta el fin de su vida ${ }^{10}$.

El problema surge cuando se trata de definir la esencia misma de ese pecado original, especialmente en relación con la concupiscencia desordenada en toda su amplitud.

Es evidente $\rightarrow$ y el luterano Julius Gross to ha demostrado con gran abundancia de citas ${ }^{11} \rightarrow$, que San Agustín tiene una doble y abundante serie de textos, a primera vista contradictorios, en sus obras antipelagianas. Contra la afirmación de Julián de Eclana, que se limitaba a definir la concupiscencia como una mera "affectio naturalis et innocens". ${ }^{12}$, Agustín emplea una nutrida gama de términos que expresan el mal de la concupiscencia: enfermedad, debilidad, vicio, mal, herida, causa del pecado (morbus, languor, infirmitas, vitium, malum, vulnus, causa peccati). Estos calificativos no engendrarían dificultad alguna al indicar únicamente que la concupiscencia es un mal y una secuela del pecado de origen. Pero hay otra serie de textos en los que San Agustín llama peccatum a la concupiscencia, siguiendo en esto la terminología paulina, especialmente de la Epístola a los Romanos. De tal modo que, refiriéndose al perdón del pecado original por el bautismo, no duda en emplear frases como ésta: El pecado original-concupiscencia pasa en cuanto al reato, pero permanece en acto, "Ut etiam illud maneat actu, praetereat reatu" (De nupt. et concup., I, 26, 29, PL. 44, 430). A estos textos de matiz paulino añade San Agustín con singular insistencia el Salmo 31, 2: Beatus vir cui non imputavit Dominus peccatum. La sola palabra

10 Die Promotionsdisputation von Petrus Hegemon (licenciatura en Teol.; 3 julio 1545), W., 39-2, 337-401. Con citas continuas de San Agustín defiende Lutero la transmisión del pecado original por generación: "ex traduce, ex propagine" (p. 395).

11 J. GRoss, "Das Wesen der Erbsünde nach Augustin": Augustinus Magister, II, 773-787.

12 Op. imperf. c. Iulianum, I, 71, PL. 45, 1.094-96; III, 67, PL. 45, 1.317; IV, 25-26, PI. 45, 1.351, etc. 
imputatio, unida ya a la concupiscencia-pecado, nos indica de antemano la procedencia de la terminología y de la doctrina luterana sobre el pecado original y la justificación forense o puramente extrínseca.

Los teólogos católicos, desde San Anselmo, Pedro Lombardo, etc., trataron ya de dilucidar esa especie de contradicción en la doctrina agustiniana, pero con muy diversos resultados. La explicación que más éxito ha obtenido hasta nuestros días es la que dio Santo Tomás, viviseccionando la esencia del pecado original en dos partes: la concupiscencia como elemento material (peccatum materiale), y la privación de la justicia original o gracia santificante como elemento formal (peccatum formale) (De Malo, q. 4, a. 2; I-II, q. 82, a. 3). Según esto, el reatus de que habla San Agustín equivaldría al pecado original en cuanto culpa; ésta se perdona en el bautismo, para recibir la gracia santificante o habitual. Por otra parte, el peccatum que permanece en acto después del bautismo sería la concupiscencia o el elemento material, que ya no es culpa, sino únicamente pena del pecado de origen. Esta es también a grandes rasgos la defensa que hizo San Roberto Belarmino de la doctrina agustiniana, al compararla con las definiciones de Trento ${ }^{13}$. Entre los teólogos de la escuela agustiniana, a pesar de algunos matices especiales, baste citar las siguientes palabras de Berti: "Peccatum originale nihil est aliud quam concupiscentia cum reatu sive vitium ex morbida qualitate contractum ab anima, cui inest reatus culpae seu privatio originalis iustitiae, adeo ut concupiscentia sit originariae culpae quasi materia, reatus vero sit illud, quod appellant theologi formale peccatum" ${ }^{14}$.

La intención de los teólogos católicos es muy plausible, pero tni ha satisfecho a los teólogos protestantes, ni responde plenamente a la mentalidåd de San Agustín y a sus categorías filosófico-teológicas.

2. La inTERPRETACión DE Lutero. -San Roberto Belarmino deja en muy mal lugar a Lutero como intérprete de esta doctrina agustiniana, cuando afirma de él: "Lutherus uno vel altero Augustini testimonio,

13 R. Belarmino, De Controversiis christianae fidei adversus huius temporis haereticos, Neapoli 1858, t. IV: De amissione gratiae et statu peccati, lib. V, c. 13,214 ss.

14 L. BerTI, De theologicis disciplinis, lib. 13, c. 5, n. 9. Cfr. J. MausBach, Die Ethik des hl. Augustinus, 2 ed., Freiburg i. Br. 1929, II, 181 ss.; J. R. ESPENBERGER, Die Elemente der Erbsünde nach Augustin und der Scholistik, Mainz. 1905; G. DíAz, O. S. A., De peccati originalis essentia in schola augustiniana praetridentina, Monasterio de El Escorial 1961; J. A. WoREK, O. S. A., De originali peccato apud Gregorium, Ariminensem, Calahorra 1964. 
eoque falso citato, contentus fuit" ${ }^{15}$. Esto resulta incomprensible, si se tiene en cuenta que el Reformador alemán toma ya de San Agustín su doctrina sobre el pecado original incluso en $155^{15}-1516$ en su exposición de la Epístola a los Romanos ${ }^{16}$. Además, Lutero le cita innumerables veces como al intérprete más fiel del Apóstol precisamente al tratar del pecado original, o mejor, de la concupiscencia en cuanto verdadero pecado hasta la muerte. $\mathrm{Y}$ no debe olvidarse que de este punto fundamental proceden como conclusiones en cadena todas las demás tesis del luteranismo: justificación extrínseca, negación del libre albedrío en el orden religioso y del mérito de las buenas obras, predestinación absoluta por parte de Dios, aniquilamiento de la ley natural, eficacia puramente psicológico-religiosa de los sacramentos, etc.

Pues bien; Lutero, anclado en un positivismo bíblico impresionante que le aclara la tragedia de su experiencia más viva, no sólo defiende con textos de San Pablo y de San Agustín que la concupiscencia o el fomes peccati es siempre en esta vida un verdadero pecado, que corrompe en el orden religioso a nuestra naturaleza, sino que llega a adoptar una definición nueva y especial del pecado. Es una concepción subjetiva y experimental, que le lleva a considerar el pecado como un estado animico, perceptible por la experiencia humana y por las vivencias y sentimientos del alma ${ }^{17}$. Como él, a pesar del bautismo y de la confesión, seguía experimentando en sí mismo la concupiscencia del pecado o la lucha cruel y constante entre la carne y el espíritu, no dudó en identificar el pecado original con la concupiscencia y en considerar como una quimera la doctrina católica del perdón de los pecados y de la renovación intrínseca del hombre por la justificación.

15. R. Belarmino, o. c., lib. V, c. 12. Cfr. J. DE Blic, "Le péché originel selon saint Augustin": Recherches de Science Religieuse 16 (1926) p. 102.

16. Ya entonces para Lutero el pecado original "est non tantum privatio qualitatis in voluntate, immo nec tantum privatio lucis in intellectu, virtutis in memoria, sed prorsus privatio universae rectitudinis et potentiae omnium virium tam corporis quam animae ac totius hominis interioris et exterioris. Insuper et pronitas ipsa ad malum, nausea ad bonum, fastidium lucis et sapientiae, dilectio autem erroris ac tenebrarum', fuga et abominatio bonorum operum, cursus autem ad malum" (Divi Apostoli ad Romanos epistola, 1.515, Die Scholien, W., 56, 312). Cfr. J. FICKER, Luthers Vorlesung über den Römerbrief 1.515-1.516, Leipzig 1908, I, 67 ss.; II, 106-111; R. HERMANN, Zu Luthers Lehre um Rechtfertigung, Tübingen 1952; B. GhERARDiNI, "El pecado en el pesimismo de la Reforma": El pecado en la filosofía moderna, Ed. Rialp, Madrid 1963, 29-87; K. Algermissen, Iglesia Católica y Confesiones Cristianas, Madrid 1964, 791 ss. 17 J. LoRTz, Historia de la Reforma, I, 182. Lo mismo puede decirse de Calvino. Cfr. J. CADIER, "Calvin et saint Augustin": Augustinus Magiser, Paris 1954, II, 1.038-1.056; ver p. 1.055 . 
Ya en el año 1520 , en la defensa de sus artículos condenados por León $\mathrm{X}$, insiste Lutero en definir esa concupiscencia-pecado o fomes peccati como una realidad positiva, viva e inquieta, como la falta de una cosa que debiera estar en el alma y la presencia en la misma de una enfermedad y de otros afectos que no debieran estar. Basta ese fomes peccati para impedir el ingreso en el cielo, y nuestro único remedio está en la misericordia de Dios que nos otorga la fe en los méritos de Cristo y no nos imputa ese pecado siempre presente en nosotros. De aquí el célebre binomio luterano simul iustus et peccator, o "partim iusti, partim peccatores", que, sin lugar a duda, inicia el camino a la dialéctica de los contrarios, tan arraigada y desarrollada más tarde por la misma filosofía idealista alemana, sobre todo por Hegel. No se olvide que Hegel y Schelling hicieron toda la carrera eclesiástica en un seminario luterano.

En el artículo tercero afirma Lutero que la concupiscencia o fomes peccati es de por sí un verdadero pecado y que, por lo mismo, aunque no haya otros pecados actuales, impide que el alma separada del cuerpo entre en el cielo: "Res enim viva et quotidie movens est peccatum, sicut et ipsa anima, in qua habitat. Nam et iustitia res est vivens et movens. sunt. Unde fit, ut, cum ipsimet concedant, abajo actuale peccatum morari ab introitu coeli, cogantur concedere, quod et fomes moretur, qui origo vivacissima et inquietissima actualium peccatorum est. Omitto hic dicere, quod originale peccatum, ut omnia peccata, ita et incredulitas est. At nemo unquam satis diligit, credit, expectat, quam diu est in carne. Spiritus enim promptus est, sed caro infirma, etiam in Apostolis: ideo fomes vere est actuale peccatum, actualis privatio sive defectus eius rei, quae adesse debet, et actualis positio seu praesentia infirmitatis et aliorum affectuum, qui deesse debent, ut vere dixerit $S$. Jacobus (I, I8), Nos esse initium creaturae Dei, nondum complementum, partim iusti, partim peccatores, hoc uno salvi et ab impiis disoreti, quod peccatum cognoscimus, confitemur et expugnamus, cui illi potius obediunt" ${ }^{18}$.

En el artículo segundo afirma que él toma esa doctrina de San Pablo, de San Agustín, cuya doctrina antipelagiana compendia e interpreta en ese sentido, de su propia experiencia y de la experiencia de todos los verdaderos santos. Enuncia así el artículo: "Negar que en el niño, después del bautismo, permanece el pecado, es machacar a Pablo y a Cristo",

18 Assertio omnium articulorum $M$. Lutheri per bullam Leonis $X$ novissiman dampratorum (1520), W., 7, 110-111; Divi Pauli ad Gal. epistola (1519), W., 2, $490,526$. 
"In puero post Baptismum negare remanens esse peccatum est Paulum et Christum conculcare" ${ }^{19}$. Para probar su tesis, Lutero se funda en que San Pablo llama pecado a la concupiscencia, y en la experiencia de todos los adultos bautizados: "Paulus (Rom. 7, 7) dicit: Concupiscentiam nesciebam esse peccatum, nisi lex diceret 'Non concupisces'. Hic sine dubio claret, concupiscentiam esse peccatum. At quis est hominum, qui concupiscentiam non sentit, postquam adoleverit, quamvis baptizatus, cum hic Apostolus sanctissimus, nedum baptizantus, suam concupiscentiam accuset? Unde ergo hoc peccatum, nisi ex nativitate carnis etiam post baptismum remanens?" ${ }^{20}$. Sigue probando con textos paulinos que el Apóstol se refiere a sí mismo, y al aducir en su favor el célebre texto de San Juan: "Si dijéremos que no tenemos pecado, nos engañamos a nosotros mismos y la verdad no está en nosotros" (I Io. I, 8), dice Lutero: "Notavit Augustinus quod non dixit 'habuimus' sed 'habemus" ${ }^{21}$. Después de exponer con negros tintes el argumento de la experiencia, nos ofrece una interpretación global de la doctrina de San Agustín sobre la relación entre el reatus y la concupiscentia-peccatum en sus obras antipelagianas. Partiendo de su concepción experimental del pecado, afirma Lutero que San Agustín refuta a los pelagianos diciéndoles que en el bautismo se perdona o pasa el reato, pero permanece realmente en acto la concupiscencia-pecado. Vale la pena citar íntegramente sus palabras: "Quid hic dicere possum, nisi quod urgentibus eodem argumento Pelagianis Augustinus dixit? scilicet peccatum remitti quo ad reatum, sed non quo ad actum, seu ut ipsius verbis utar, Peccatum istud reatu transit, actu manet. Sicut enim, ut idem ait, aliquod peccatum transit actu et reatu (sicut est omne actuale), ita econtra hoc originis peccatum transit reatu et manet actu. Ecce non negat esse peccatum, nec dicit solum defectum aut poenam esse, sed peccatum actu et vere esse. Rursum dicent, 'At nos reatum hunc proprie vocamus peccatum, non illud quod remanet'. Respondeo: In re ista seria et sacra non licet argutiis sophisticis cavillari, quibus effingunt reatum esse respectum inter Deum et peccatorem, quo hic deputatur ad poenam. Iniuria est gratiae Dei, si solum istum pahntasticum respectum tollere doceatur, cum, ut Scriptura loquitur, gratia Dei renovet, mutet et in novos homines transformet

19 W., 7, 103; Resolutiones Lutherianae super propositionibus suis Lipsiae disputatis (1519), W., 2, 410.

20 W., 7, 103; Ein Sermon von hl. hochwürdigen Sacrament der Taufe (1519), W., 2, 727-727; Rationis Latomianae Confutatio (1515), W., 8, 37-128.

21 W., 7, 107. 
de die in diem, et res ista serio agatur non respectibus tollendis, sed substantia et vita mutandis. Nam ideo corpus mori et incinerari oportet, ut peccatum expurgetur: verus est morbus et serius, qui tam seriam et potentem exigit medicinam" 22 .

El único perdón de ese reato consiste para Lutero en que Dios, por su misericordia, no imputa ese pecado siempre real a aquellos a los que ha otorgado la fe en los méritos de Cristo. Por eso son al mismo tiempo justos y pecadores: "Ita simul verum est, iustum non peccare, et tamen peccatum habere seu malum facere". Y concluye tomando del mismo San Agustín su doctrina de la no imputación del pecado: "Concludamus ergo cum pulcherrimo verbo Augustini: Peccatum, inquit, remittitur in baptismo, non ut non sit, sed ut non imputetur. Ecce est et remanet peccatum, sed non imputatur: quare perseverandum est in usu Scripturae et antiquorum, et non defectum sed vere peccatum appellandum libidinem et alias passiones reliquas baptismo. Et aliud esse omnia peccata remitti, aliud omnia tolli. Baptismus omnia remittit, sed nullum penitus tollit, sed incipit tollere, id quod illos fefellit, qui remissionem intellexerunt omnimodam expurgationem, ac sic defectum pro peccato accipere se ipsos coegerunt, ex malo intellectu in peiorem lapsi" ${ }^{23}$. Esta interpretación agustiniana de Lutero se conservará en toda su inmensa obra y, según el teólogo luterano de la "Sammlung", Ernst Kinder, ha sido recogida en todas las profesiones de fe luteranas con referencias explícitas a San Agustín ${ }^{24}$.

Aunque Lutero adoptó desde muy pronto el principio de la "sola Scriptura", cualquier lector precavido habrá podido observar que sus tesis fundamentales proceden de la que él creyó auténtica interpretación agustiniana de San Pablo. Sería injusto poner en duda su honradez. Por eso creemos de suma importancia hacer una breve comparación entre la doctrina de Lutero y la del Obispo de Hipona, fuente de tantas opiniones encontradas en el transcurso de los siglos.

En primer lugar, no creemos lícito el método de aferrarse exclusivamente a una de las dos series de textos agustinianos sobre el pecado

22 W., 7, 109; Enarrat. Psalmi 51, W., 40-2, 351-352; W., 56, 263, 272; W., 3, 199.

23 W., 7, 109-110.

24 E. KINDER, Die Erbsünde, Stuttgart 1959. "Auf Augustinus berufen sich die Bekenntnisschriften hier wie sonst öfter und führen ihn gegen die Scholastiker ins Feld: z. B. Apologie II, 24 ff." (p. 43). Cfr. Z. AlszeGHy, S. J., "Il peccato originale nelle professioni di fede luterane": Gregorianum 47 (1966) 86-100. 
original y la concupiscencia. Esto no es honesto ni objetivo. Pero tampoco es lícito atribuir al Santo Doctor una infinidad de textos contradictorios, casi a renglón seguido, sencillamente porque no se logra comprenderle. Hoy día tenemos medios de interpretación mucho más perfectos que los del siglo xvi, y debemos usarlos con la mayor precisión posible. Dar a la terminología agustiniana un sentido escolástico equivale en general a tergiversar por completo su pensamiento.

3. La CONCUPiscencia como "PEccatum" y el neoplatonismo de SAN Agustín.-Se ha de advertir ante todo que la doctrina agustiniana sobre el pecado original refleja fielmente la terminología y la doctrina de la sagrada Escritura, especialmente de San Pablo, así como su propia experiencia filosófico-religiosa. Por lo tanto, aunque su neoplatonismo es de suma importancia para descifrar las contradicciones aparentes de sus expresiones, no puede ser considerado aquí como la fuente decisiva de su doctrina. La antropología neoplatónica y su catarsis de tipo esencialmente gnoseológico tienen en Agustín un sentido profundamente cristiano.

Ya hemos indicado antes que San Agustín llama con mucha frecuencia "peccatum" a la concupiscencia, glosando los textos del Apóstol. Sin embargo, tiene también un sin fin de pasajes en los que nos dice expresamente que San Pablo llama pecado ( $\left.\dot{\mu} \times x_{\rho} r i x\right)$ a la concupiscencia sólo porque ella es la fuente y raíz de todos los pecados: "Peccati autem nomine quod in illo habitabat, ipsam nuncupabat concupiscentiam; quia peccato facta est, et si consentientem traxerit atque illexerit, concipit paritque peccatum" ${ }^{25}$. Del mismo modo, la concupiscencia es un mal (malum), porque es la causa de todos los males, y es un vicio (vitium) por ser la causa de todos los vicios: "Nam quis praeter vos cupiditatem negat esse malam, qua cupiuntur mala? quis, inquam, praeter vos per-

25 Contra Iul., VI, 23, 73, PL. 44, 868. Hay una serie innumerable de textos en este sentido. "Quae alio modo peccati nomen accepit" (De perf. iust. homi nis, 21, 44, PL. 44, 316); 6, 12, PL. 44, 297; 11, 28, PL. 44, 305-306; "Modo quodam loquendi peccatum vocatur" (De nupt. et concup., I, 23, 25, PL. 44, 428); "Sed haec etiamsi vocatur peccatum, non utique quia peccatum est, sed quia peccato facta est, sic vocatur sicut scriptura manus cuiusque dicitur quod manus eam fecerit... Eit ideo iam non sit peccatum, sed hoc vocetur sive quod peccato facta sit, sive quod peccandi delectatione moveatur, etsi ei vincente delectatione iustitiae non consentiatur" (Contra duas epist. Pelag., I, 13, 27, PL. 44, 563); Op. imperf. c. Iul., I, 71, PL. 45, 1.096; I. 72, PL. 45, 1.098; III, 210, PL. 45', 1.336 ; De pecc. mer. et remiss., II, 22, 36, PL. 44, 173; De nat. et gr., 38, 45, PL. 44, 269; 56, 66, PL. 44, 280; 62, 72, PL. 44, 283; In Ps. 118, ser. 3, 2, PL. 37, 1.507; S. $155,1,1$, PL. 38, 841 . 
suadere conatur non esse vitium, quam cupiditatem confitetur esse vitiorum; et non esse malum, cui suadenti si consentiatur fit opus malum?" 26 .

$\mathrm{Si}$ a esto se añade la serie innumerable de textos en los que San Agustín nos dice que por el bautismo se perdonan el reato de la concupiscencia y todos los demás pecados, y que la praxis eclesiástica de bautizar también a los niños nos indica la pecaminosidad universal de ese reato, pero que la concupiscencia-pecado permanece en acto después del bautismo, nos encontramos ante una contradicción, o mejor, ante la dialéctica de los contrarios de Lutero, en la que ambos términos opuestos son a su vez una garantía mutua. Si la terminologa agustiniana se toma en sentido escolástico, es preciso admitir que en los bautizados hay pecado y no hay pecado; de este modo, la no imputación de Lutero deshace el nudo de la contradicción mucho mejor que las distinciones de los católicos. Pero la cuestión es mucho más rica de sentido y confirma, a pesar de todo, la doctrina católica proclamada en el concilio de Trento.

Ya en el Congreso Internacional Agustiniano de París (1954), hizo notar el P. E. Hendrikx, O. S. A., que en el contexto platónico de los Santos Padres y en la teología bíblica el concepto de peccatum no implica en general la idea de una ética o de culpabilidad moral, que recibió más tarde en la teología y filosofía escolásticas. De ahí que los Santos Padres, especialmente San Agustín, hablen sin complicaciones de un peccatum naturae ${ }^{27}$. Bastaba la constatación existencial de un desorden interno, de una lucha continua entre la carne y el espíritu que enfrenta al hombre con su Creador, para poder hablar de un pecado de naturaleza. Para ei neoplatónico, todo quebranto del orden y de la armonía de las cosas constituía ya un pecado, un mal, un vicio, una imagen deforme que no reflejaba la perfección del ejemplar supremo.

Ciertamente, esta constatación es de suma importancia para dilucidar la cuestión que nos ocupa, pero no explica del todo la paradoja agustiniana. No en vano Lutero la llamó ya "paradoja teológica" en la Controversia de Heidelberg, según vimos antes.

En nuestra opinión, teniendo en cuenta otros casos análogos de la doctrina agustiniana, la terminología platónica y una cierta base filosó-

26 Op. imperf. c. Iul., IV, 48, PL. 45, 1.366; IV, 61, PL. 45; 1.375; V, 19, PL. 45, 1.452.

27 E. Hendrikx, O. S. A., “Platonisches und biblisches Denken bei Augustinus": Augustinus Magister I (Paris 1954) 285-292. 
fica del mismo signo juegan aquí un papel mucho más decisivo. Toda la obra agustiniana está como impregnada de un principio neoplatónico, por él cristianizado, que le sirve de substrato: Es la teoría neoplatónica de la participación, que implica al mismo tiempo el concepto de causalidad ejemplar y eficiente. Toda realización concreta de una Idea en el mundo creado acusa la presencia y la causalidad ejemplar y eficiente de la Idea Suprema. En el platonismo, ambas cosas, la realización concreta limitada y la Idea Suprema, reciben el mismo nombre y solamente por el contexto es posible entrever la distinción real que las discierne en sí y en sus propiedades. En otros lugares hemos expuesto ampliamente esta cuestión fundamental para comprender rectamente el pensamiento de San Agustín. Es la misma relación que él establece, por ejemplo, entre el Espíritu Santo, Caridad, y nuestra caridad participada, que causó tantos titubeos a Pedro Lombardo, a Petavio y al mismo De Régnon; o entre el Verbo, Sabiduría de Dios, y nuestra sabiduría participada ${ }^{28}$. La misma doctrina agustiniana del carácter sacramental, al que Agustín llama con frecuencia sacramentum, obedece sin duda a ese intercambio mutuo de nombres y de propiedades en la teoría neoplatónica de la participación ${ }^{29}$.

Pues bien; si no queremos admitir un sinnúmero de contradicciones en la doctrina agustiniana sobre el pecado original, y si tenemos en cuenta que San Agustín dice con insistencia que la concupiscencia es pecado en acto por ser causa de todos los pecados, mal y vicio por ser causa de todos los males y vicios, y que en el bautismo se perdona su reato y todos los demás pecados, es preciso admitir que el término peccatum tiene para él en este caso, al igual que en San Pablo, el sentido neoplatónico de causa ejemplar y eficiente de todos los pecados. Por eso llama indistintamente peccatum a la causa (concupiscencia) y a sus efectos (los pecados actuales), y sólo por el contexto podemos discernir cuándo ese término implica el concepto de una verdadera culpabilidad moral ante Dios (reatus), o no.

En este sentido, es válida la interpretación de Santo Tomás y de la mayor parte de los teólogos católicos, según. la cual el reatus que se per-

28 A. Turrado, O. S. A., "El platonismo de San Agustín y su doctrina acerca de la inhabitación del Espíritu Santo": Augustiniana 5 (1955) 471-486; Id., "Eres templo de Dios. La inhabitación de la Sma. Trinidad en los justos según San Agustín": Revista Agustiniana de Espiritualidad 7 (1966) 330-381. 29 A. TURRAD0, "El carácter sacerdotal según San Agustín": Augustinus 12 (1967) 403-422. 
dona en el bautismo es la culpabilidad moral de la concupiscencia, aunque ésta continúe presente y activa en el bautizado como lucha entre la carne y el espíritu y como raíz de todos los demás pecados actuales. Es una interpretación objetiva en cuanto a la doctrina, si bien no llega a resolver plenamente ia paradoja agustiniana por falta de una perspectiva neoplatónica. En cambio, la interpretación de Lutero y de sus seguidores que, a primera vista, parece mucho más fiel al pensamiento de San Agustín, aunque sea muy comprensible en el siglo xvi, hoy debe ser revisada de lleno a la luz de los nuevos métodos de exégesis bíblica y patrística. Es lo que han tratado de hacer los componentes del grupo luterano "die Sammiung", según puede verse en el libro antes citado de Ennst Kinder.

Pero hay otro aspecto de la doctrina agustiniana sobre el pecado que es preciso mencionar, al menos brevemente, porque viene a corroborar cuanto llevamos dicho hasta el momento. Se trata del concepto agustiniano del pecado actual.

4. Concepto agustiniano del "peccatum actuale" y su interPRETACión POR Lutero.-La conclusión lógica de la doctrina de Lutero sobre la concupiscentia-peccatum es que, por el pecado original, nuestra naturaleza quedó empecatada, corrompida (verdorben), privada del libre albedrío para todo jo referente a la salvación. Y Lutero sacó esa conclusión lógica con creces, atribuyédola también a San Agustín. Si el hombre, por el pecado original, está corrompido y privado del libre albedrío para el bien, todas sus obras son de por sí pecados, del mismo modo que el árbol malo no puede dar más que frutos malos. Sólo que la misericordia de Dios, por los méritos de Cristo, no les tiene en cuenta esos pecados y, por lo mismo, tanto la persona como las obras de los justos son al mismo tiempo buenas y malas o pecaminosas: "Ac per hoc persona ipsa iusti partim est iusta, partim peccatrix. Si ergo omnis persona simul peccatrix est, dum iusta est, quid evidentius sequi potest quam ut opus quoque partim sit bonum, partim malum? Cum Christus dicat et natura monstret, talem esse fructum, qualis est arbor, vitium arboris certe in fructu sentitur" ${ }^{30}$.

Recogiendo a su modo la doctrina de San Agustín contra los pelagianos, y en parte con fidelidad, afirma Lutero que esas obras de los justos no son meros defectos, sino verdaderos pecados por ir contra el pre-

$30 \quad$ Assertio omnium articulorum..., W., 7, 137. 
cepto de amar a Dios de todo corazón, con todas las fuerzas y con toda el alma: "Est enim omissio illius praecepti, 'Diliges Dominum Deum tuum ex toto corde tuo...' (Mc. 12, 30). Cum autem caro resistat spiritui, clarum est, quod vires carnis non diligant Deum, ac per hoc peccant in hoc praeceptum" ${ }^{31}$. Fundándose en San Agustín, en San Gregorio y en la misma Escritura, termina diciendo que "la obra buena bien hecha es pecado venial según la misericordia de Dios, pero es pecado mortal según el juicio de Dios" ${ }^{32}$. De ahí también su artículo 36 , en eì que niega la existencia del libre albedrío después del pecado como no sea para pecar mortalmente: "Liberum arbitrium post peccatum res est de solo titulo, et dum facit, quod in se est, peccat mortaliter" ${ }^{33}$. Acusa al Papa y a los teólogos desde 300 años atrás de haber defendido el pelagianismo al enseñar que el hombre puede prepararse para recibir la gracia mediante las obras moralmente buenas. Esto va, según él, contra la doctrina de San Pablo y de San Agustín: "Est autem articulus nixus primo in verbo Augustini de Spiritu et Littera, c. 4, 'Liberum arbitrium sine gratia non valet nisi ad peccandum'. Rogo, quae est ista libertas, quae non nisi in alteram partem potest eamque peiorem? Est hoc esse liberum, non posse nisi peccare? Sed Augustino non credam. Scripturas audiamus, etc." ${ }^{34}$. Esta doctrina de Lutero sobre el pecado y el libre albedrío se conserva intacta en toda su obra: en su Comentario a los siete Salmos Penitenciales de $1_{51} 7^{35}$, en la Controversia de Heidelberg de ${ }^{15} 5^{136}$, en el Tratado de la libertad cristiana de ${ }^{1520^{37}}$, y de un modo especial en su De servo arbitrio de 1525, contra Erasmo ${ }^{38}$, etc.

Será preciso recurrir aquí al concepto agustiniano del pecado actual en relación con la concupiscencia desordenada. Porque, si bien el Santo distingue con cierta frecuencia los pecados actuales en mortales y veniales, también aquí su concepto de peccatum sobrepasa con mucho el sentido que le da la moral posterior.

Cuando San Agustín afirma que todas las obras de los justos son de algún modo pecados, no hace más que reproducir la doctrina de la Escri-

\footnotetext{
$31 \quad$ Ib., W., 7, 137.

32 "Opus bonum optime factum veniale peccatum est secundum misericordiam Dei, sed mortale peccatum secundum iudicium Dei" (Ib., W., 7, 138-139).

$33 \quad I b .$, W., 7, 142.

34 Ib., W., 7, 142.

35 W., 1, 154-220.

36 W., $1,350-365$.

37 W., 7, 39-73.

38 W., 18, 600 ss.
} 
tura, especialmente de la primera Epístola de San Juan, con ese matiz neoplatónico de falta de armonía perfecta con el ideal del bien, según indicamos antes. Por eso, como después del pecado de origen estamos todos sujetos a la concupiscencia desordenada, todas nuestras obras padecen al menos de una falta de intensidad en la caridd debida $\mathrm{y}$, por lo mismo, pueden llamarse pecados. Nos lo dice bien claramente en su obra De perfectione iustitiae hominis, con expresiones que agradarán sin duda a los moralistas modernos: "Peccatum est autem, cum vel non est caritas quae esse debet, vel minor est quam debet, sive hoc voluntate vitari possit, sive non possit: quia si potest, praesens voluntas hoc facit: si autem non potest, praeterita voluntas hoc fecit; et tamen vitari potest, non quando voluntas superba laudatur, sed quando humilis adiuvatur" 39 .

Precisamente, la concupiscencia que afecta a todo el hombre, carne y espíritu, es la causa de que falte siempre algo a la perfección de nuestra caridad mientras peregrinamos por esta vida. Sin embargo, San Agustín afirma que era conveniente proponernos ya desde ahora el ideal futuro para que sepamos hacia dónde se dirigen nuestros pasos: "Nam cum est adhuc aliquid carnalis concupiscentiae, quod vel continendo frenetur, non omni modo ex tota anima diligitur Deus. Non enim caro sine anima concupiscit, quamvis caro concupiscere dicatur, quia carnaliter anima concupiscit. Tunc erit iustus sine ullo omnino peccato, quando nulla lex erit in membris eius repugnans legi mentis eius (Rom. 7, 23), sed prorsus toto corde, tota anima, tota mente diliget Deum, quod est primum summumque praeceptum (Mt. 22, 37-38). Cur ergo non praeciperetur homini ista perfectio, quamvis eam in hac vita nemo habeat? Non enim recte curritur, si quo correndum est nesciatur" ${ }^{40}$. Estos mismos conceptos se encuentran con frecuencia en todas sus obras antipelagianas, especialmente en el De natura et gratia. Cualquier lector menos precavido podría creer que se halla a veces frente a la dialéctica luterana de los contrarios, a leer frases como ésta: "Verum quia saepe in levissimis et aliquando incautis obrepit peccatum; et iusti fuerunt, et sine peccato non fuerunt" ${ }^{41}$. Evidentemente, el Santo se refiere aquí a esa falta de la caridad debida que mengua la perfección de todas las obras de los jus-

39 De perf. iust. hominis, 6, 15, PL. 44, 298.

40 Ib., 8, 19, PL. 44, 301; De gr. Christi et de pecc. orig., I, 11, 12, PL. 44, 366-367.

41 De nat. et gr., 38, 45, PL. 44, 269. 
tos en esta vida sujeta a la concupiscencia, pero que no son en modo alguno pecados mortales ni ante la misericordia, ni ante el juicio de Dios, según pretende Lutero. En este contexto agustiniano tiene una importancia singular la excepción expresa y única de la Virgen María, "de qua propter honorem Domini nullam prorsus, cum de peccatis agitur, haberi volo questionem" 42 .

Quedan aquí flotando aún varias cuestiones íntimamente relacionadas con el pecado original, como la justificación, el mérito de las buenas obras y la predestinación, pero en realidad todas ellas dependen de la anterior sobre la concupiscentia-peccatum. Además, el tema de la imagen de Dios en el hombre, del que nos ocuparemos a continuación, las incluye de algún modo a todas ellas.

III. La doctrina agustiniana de la imagen de Dios y las tesis de LUTERO SOBRE EL PECADO ORIGINAL Y LA JUSTIFICACIÓN.

Bien podemos afirmar con algún autor moderno que la doctrina agustiniana de la imagen de Dios en el hombre fue una de las preocupaciones más serias de Lutero durante toda su vida. No podía ser de otro modo, dada su íntima relación con la justicia original en que fue creado el primer hombre. Para Lutero, esa justicia original de Adán era algo natural o connatural, que formaba parte integrante de la plenitud de la naturaleza humana. Por eso, al perder esa justicia por el pecado, la naturaleza humana quedó de algún modo incompleta e intrínsecamente corrompida. Esto no se ha de entender en sentido escolástico, como si nuestra naturaleza hubiera quedado metafísicamente menguada, sino en sentido psicológico-religioso; pero ya es una cosa muy grave decir que la naturaleza humana perdió su plenitud natural por el pecado, y que esa deficiencia radical es innata (eingeboren) en todos los descendientes de Adán. "La justicia original de Adán, dice Lutero, no era un don extrínseco y separado de la naturaleza del hombre; era algo natural, perteneciendo a la naturaleza de Adán el amar a Dios, creer en él y reconocerle, etcétera. Estas cosas eran tan naturales en Adán, como es natural que los ojos vean la luz" ${ }^{48}$.

42 Ib., 36, 42, PL. 44, 267.

43 In I Librum Mose Enarrationes, W., 42, 123-127; Enarrat. Psalmi 51 (1532), W., 40, 323 ss. 
Para Lutero, al igual que para los teólogos luteranos y calvinistas, incluso modernos, como Emil Brunner, $\mathrm{H}$. Thielicke, Karl Barth, etc., esto equivale a la pérdida de la imagen divina del hombre ${ }^{44}$. Nada hay más en consonancia con los textos antimaniqueos de San Agustín, que hablan de la pérdida de la imagen de Dios por el pecado de Adán. Pero hay en el fondo una diferencia radical, porque tanto San Agustín como los maniqueos de su tiempo se situaban exclusivamente en un contexto paulino, es decir, en un plano sobrenatural de la imagen de Cristo, hombre nuevo, por contraposición a Adán, hombre viejo. Sin embargo, cuando hacia el año $4 \mathrm{I} 2$ comenzó a dilagar el error pelagiano con su optimismo naturalista, el Santo Doctor se vio obligado a insistir en el aspecto natural de la imagen divina, oscurecida, debilitada, envilecida y deformada por el pecado de origen, pero no del todo perdida. Esa diferente postura de San Agustín, debida al carácter opuesto del maniqueismo y del pelagianismo, explica con creces lo que algunos pretendían calificar de contradicciones ${ }^{45}$. Tratándose de un genio como Agustín, es ese un método muy peligroso, sobre todo si se tiene en cuenta que hacia el fin de su vida escribió unas Retractationes.

Pues bien; tanto Lutero, como los teólogos católicos que se han debatido entre sí sobre la esencia del pecado original en la doctrina agustiniana, no comprendieron el alcance profundo de su exposición en torno a la imagen trinitaria del hombre, especialmente tal como la desarrolla en los últimos libros del De Trinitate. El mismo M. Schmaus se limitó a vagar por el campo de la psicología, aunque a veces parezca lo contrario, en su obra Die psychologische Trinitätslehre des hl. Augustinus (Münster, 1927), si bien en algunos artículos recientes ha corregido en parte su postura ${ }^{46}$.

Lutero, ya en sus años maduros (I535-I545), explicaba en la universidad de Wittenberg el Pentateuco, y al llegar a los versículos 26 y 27 del cap. I del Génesis: "Hagamos ai hombre a nuestra imagen y semejanza", se detuvo a examinar la doctrina de San Agustín sobre este par-

44 In I Librum Mose Enarrat., W., 42, 46 ss. Cfr. E. BRunNer, Der Mensch im Widerspruch, 3 ed., Zürich 1941, 530 ss.; Id., Dogmatik, Zürich 1950, 66-70; H. THIELICKE, Theologische Ethik, I, Tübingen 1951, nn. 812 y 949; K. BARTH, Kirchliche Dogmatik, III/2, 1948, p. 20; O. W EBER, Grundlagen der Dogmatik, I, Neukirchen 1955, 118-119.

45 A. TuRrado, "Nuestra imagen y semejanza divina. En torno a la evolución de esta doctrina en San Agustín": La Ciudad de Dios 181 (1968) 776-801.

46 A. Turrado, "Eres templo de Dios...": Revista Agustin. de Espiritualidad 7 (1966) 377 ss.; 8 (1967) 363-406. 
ticular, aunque sin mucho entusiasmo, porque ve que los teólogos católicos deducen de ella la existencia del libre albedrío después del pecado en el orden de la salvación. Cremos muy conveniente seguir de cerca los pasos de Lutero, porque en realidad nos vuelve a ofrecer aquí un resumen de sus tesis fundamentales.

Después de resumir la doctrina de San Agustín, expuesta en el De Trinitate, sobre esa imagen trinitaria en la tríada de potencias del alma humana (memoria, entendimiento y voluntad), y de observar con cierto disgusto que en esto San Agustín conserva la división de Aristóteles ${ }^{47}$, pasa a analizar lo que dicen los católicos del concepto de semejanza o similitudo, que sería una perfección de la imagen en el orden de la gracia ${ }^{48}$. Supongo que Lutero se referirá aquí a los teólogos católicos, porque en realidad San Agustín identifica fundamentalmente ambos conceptos de imago y similitudo, corrigiendo expresamente en esto a Orígenes y a otros Padres que le siguen ${ }^{49}$.

Lutero no hace mucho aprecio de esa búsqueda en torno a la imagen divina del hombre, sino que la considera más bien ociosa e inútil, sobre todo porque los teólogos católicos pasan de ahí a demostrar la existencia del libre albedrío en el orden de la saivación: "Nam huc quoque affertur disputatio de libero arbitrio, quae ex imagine ista nascitur". Además, surgen de ahí muchas opiniones incómodas, como la de citar este texto de San Agustín para defender el libre albedrío: "Deus, qui creavit te sine te, non salvabit te sine te". (Se ve que todos citaban de memoria, porque Agustín dice en realidad "non te iustificat sine te": Sermo i69, I I, I3, PL. 38, 923). Y esto, dice Lutero, no puede atribuirse en modo

\footnotetext{
47 Quid sit imago illa Dei, ad quam Moses hominem dicit factum esse? Ac Augustinus in hoc loco explicando multus est, praesertim in libro De Trinitate. Doctores autem reliqui fere Augustinum sequuntur, qui Aristotelis divisionem retinet, quod imago Dei sint potentiae animae, memoria, mens vel intellectus, et voluntas; in his tribus dicunt consistere imaginem Dei, quae in omnibus hominibus est. Sicut enim in divinis, inquiunt. verbum nascitur ex substantia Patris, et Spiritus sanctus est complacentia patris: Ita in homine ex memoria procedit verbum cordis, quod est mens; Eo producto prodit voluntas, quae videt menteml et ea delectatur (In I Lib. Mose Enarrat., W., 42, 45).

48 Similitudinem autem dicunt esse in donis gratuittis. Sicut enim similitudo est quaedam perfectio imaginis, ita dicunt naturam perfici per gratiam. Itaque similitudo Dei est, quod memoria ornatur spe, intellectus fide, et voluntas caritate. Ad hunc modum, inquiunt, homo est creatus ad imaginem Dei, hoc est, homo habet mentem, memoriam et voluntatem. Item, homo est creatus ad similitudinem Dei, hoc est, intellectus est illuminatus fide, memoria confirmata spe ac constantia, et voluntas ornata caritate (Ib., W., 42, 45).

49 Cfr. R. A. Markus, "Imago and Similitudo in Augustine": Revue des Etudes Augustiniennes 10 (1964) 125-143.
} 
alguno a las fuerzas de la naturaleza ${ }^{50}$. El se limita a recomendar mucha prudencia al leer esas expresiones de los Santos Padres, porque estos vivían en otros tiempos y daban a sus palabras un afecto y sentido que nosotros no podemos darles ni comprender hoy ${ }^{51}$. $Y$ opina repetidas veces que en esta vida ya no podremos comprender en qué consistió esa imagen perdida por el pecado.

Tenemos la memoria, la mente y la voluntad corrompidísimas y gravísimamente debilitadas, o mejor, completamente leprosas e inmundas (prorsus leprosa et immunda). Satanás las tiene mucho más esbeltas que nosotros, y no vamos a decir por eso que él fue creado a imagen de Dios $^{52}$. A continuación, pasa a exponer las maravillas del estado de Adán antes del pecado, tanto en sus potencias espirituales como en su mundo exterior, y se conforma con definir la imagen divina como un conocimiento y fe profunda en la bondad de Dios y como un estado felicísimo, libre de todo peligro y del miedo de la muerte ${ }^{53}$. Una vez que todo ha caído y ha sido corrompido por ei pecado, sólo nos resta acogernos al

50 Lutero no reprueba esa diligencia y esos pensamientos referentes a la Trinidad, "tamen haud scio, an sint valde utiles, praesertim cum ea postea longius ducantur. Nam huc quoque affertur disputatio de libero arbitrio, quae ex imagine ista nascitur. Ita enim dicunt: Deus est liber, ergo cum homo ad imaginem Dei sit conditus, habet etiam liberam memoriam, mentem et voluntatem. Ad hunc modum multa excidunt, quae aut improprie dicuntur, aut postea impie accipiuntur. Ita nata est hinc periculosa sententia, qua pronuntiant Deum ita gubernare homines, ut eos proprio motu sinat agere. Ex hoc dicto multae incommodae opiniones enatae sunt. Simile est, quod citatur: Deus, qui creavit te sine te, non salvabit te sine te. Hinc conclusum est: liberum arbitrium concurrere tanquam causam praecedentem et efficientem salutis. Non dissimile est Dionysii dictum, periculosius superioribus, ubi dicit: Quanquam daemones et homo ceciderunt, inquit, tamen naturalia manserunt integra, ut sunt mens, memoria, voluntas, etc. Sed si hoc verum est, sequitur, quod homo viribus naturae possit facere, ut salvus fiat (In I Lib. Mose, W., 42, 45).

$51 \quad I b .$, W., 42, 45-46.

52 Vereor autem, ne, postquam haec imago per peccatum amissa est, non satis eam possimus intelligere. Memoriam, voluntatem et mentem habemus qui$\mathrm{dcm}$, sed corruptissima et gravissime debilitata, imo, ut clarius dicam, prorsus leprosa et immunda. Si enim istae potentiae sunt imago Dei, sequetur etiam Satanam ad imaginem Dei conditum esse, qui profecto illa naturalia longe habet validiora, quam nos habemus, sicut est memoria et intellectus summus et voluntas obstinatissima. Ergo est imago Dei longe aliud, nempe opus Dei singulare. $\mathrm{Si}$ qui tamen contendunt has potentias esse imaginem istam, fateantur eas quasi leprosas et immundas esse. Sicut leprosum hominem tamen hominem appellamus, quanquam in carne leprosi omnia pene mortua sunt et stupent, nisi quod ad libidinem commoventur vehementius ( $I b ., W ., 42,46)$.

53 Ergo imaginem Dei sic intelligo: Quod Adam eam in sua substantia habuerit, quod non solum Deum cognovit et credidit eum esse bonum, sed quod etiem vitam vixerit plane divinam, hoc est, quod fuerit sine pavore montis et omnium periculorum, contentus gratia Dei. Sicut in Heva apparet, quae cum serpente sine omni mietu loquitur sicut nos cum agno aut cane. Ideo etiam istam poenam proponit Deus, si transgrediantur praeceptum: 'Quacumque die comederis ex ligno hoc, morte morieris', quasi dicat: Adam et Heva, vos nunc vivitis 
Evangelio para que nos sitúe en el camino de la esperanza de la vida eterna, por la fe en los méritos de Cristo ${ }^{54}$. En realidad, Lutero vuelve a adherirse exclusivamente a la concepción que San Agustín tenía de la imagen divina del hombre en los primeros escritos de su vida, con un marcado acento neoplatónico de fácil dinamismo espiritual, de incorruptibilidad o sumisión de la carne al espíritu y de ausencia de todo dolor físico y moral.

Precisamente, la doctrina de San Agustín sobre la imagen en sus obras antipelagianas y en los últimos capítulos del De Trinitate, escritos en la misma época, podía haber sido una revelación para Lutero. Porque esa imagen, que radica en la ontología vital del espíritu humano, es la que expresa con más claridad el equilibrio agustiniano entre la naturaleza y la gracia, y la que implica con creces el ontologismo de la justificación, proclamado más tarde por el concilio de Trento. Además, Lutero podía haber visto en esa doctrina que la escatología agustiniana comienza por ser ya una realidad en esta vida, y no una pura esperanza de la vida futura ${ }^{55}$. Pero tal vez era ya demasiado tarde. Porque Lutero partió siempre del concepto de la concupiscentia-peccatum, que él creyó auténticamente paulino y agustiniano, y todo lo demás estaba condicionado por el mismo; las expresiones paulinas y agustinianas que parecen indicar un verdadero perdón de los pecados ya en esta vida y una renovación interna por la gracia, serán para él una simple no imputación del pecado por la misericordia de Dios y una pura benevolencia divina sin renovación alguna por parte del hombre; el misterio de la libertad y de la gracia que se refleja tan vivamente en los dos corifeos del cristianismo, será para Lutero únicamente el monomio de la gracia o benevolencia divina. Es más; si en la sagrada Escritura encuentra

securi, mortem non sentitis nec videtis. Haec est imago mea, qua vivitis, sicut Deus vivit. Si autem peccaveritis, amittetis hanc imaginem et moriemini (In I Lib: Mose, W., 42, 47):

54 Sed pfecati originalis ista culpa est, quo vitium contraxit tota reliqua creatura, ut solem ante peccatum clariorem, aquam puriorem, arbores fertiliores, agros foecundiores esse existimem. Per peccatum autem et illum horribilem lapsum non solum caro lepra peccati deformata est, sed omnia, quibus haec vita utitur, corrupta sunt, sicut infra clarius dicemus. Hoc autem nunc per Evangelium agitur, ut imago illa reparetur. Manserunt quidem intellectus et voluntas, sed valde viciata utraque. Evangelium igitur hoc agit, ut ad illam et quidem meliorem imaginem reformemur, quia in vitam aeternam vel potius in spem vitae aeternae renascimur per fidem, ut vivamus in Deo et cum Deo, et unum cum ipso sumus, sicut Christus dicit. Neque vero ad vitam solum renascimur sed etiam ad iustitiam, quia fides arripit meritum Christi et statuit nos per Christi mortem liberatos esse (Ib., W., 42, 48).

55 Cfr. la nota 28. 
algunas frases irreconciliables con esa postura radical, como las de la Epístola de Santiago (la fe sin las obras está muerta), no duda Lutero en rechazar la autenticidad de la misma, porque la considera opuesta a San Pablo y al Evangelio. Las dudas de sus correligionarios más destacados le parecen fuera de lugar ${ }^{56}$. Será ésta una postura subjetivamente honesta, pero de consecuencias incalculables, que deben servirnos de invitación a revisar muchas cosas del pasado. Es preciso insistir en el respeto al misterio tanto en la teología protestante como en la católica. La justa armonía entre la libertad y la gracia nos resulta incomprensible, pero también lo fue para San Agustín. El no duda en confesarlo con toda humildad ${ }^{57}$. En cambio, las duras y prolongadas polémicas de los teólogos católicos en torno a la naturaleza de la gracia eficaz (de auxiliis) se alejaron con demasiada frecuencia de esta perspectiva, y Lutero negó sin más uno de los polos que integran el misterio, el libre albedrío, aniquilando así toda colaboración del hombre en la obra de su salvación ${ }^{58}$. Esto no puede ser. $\mathrm{O}$ se respeta profundamente este misterio y se salva el diálogo consciente y responsable del hombre con su Dios y Creador, a través de Jesucristo, o el cristianismo se convertirá irremediablemente en una religión incompatible con las aspiraciones más íntimas del hombre.

IV. Replanteamiento de la cUestión aNTe el eCUMEnismo moderno.

El nuevo ambiente ecuménico, promovido por los últimos Papas y por el Vaticano II, nos invita a hacer algunas breves consideraciones sobre el pecado original y sus consecuencias. Es un tema que no podemos pasar en silencio en una hora como ésta.

I. Ante las nuevas perspectivas de la exégesis bíblica y del evolucionismo científico moderno, que van imponiendo con tanta rapidez la desmitologización de ciertos relatos bíblicos, como los primeros capítulos

56 Cfr. P. Bergauer, Der Jakobusbrief bei Augustinus, Wien 1962.

57 Sed quia ista quaestio, ubi de arbitrio voluntatis et Dei gratia disputatur, ita est ad discernendum difficilis, ut quando defenditur liberum arbitrium, negari Dei gratia videatur; quando autem asseritur Dei gratia, liberum arbitrium putetur aufferri (De gr. Chrissti et de pecc. orig., I, 47, 52, PL. 44, 383). Cfr. R. Garrigou-Lagrange, O. P., "L'équilibre supérieur de la pensée de saint Augustin dans les questions de la grâce": "Augustinus Magister", II, 763-771.

58 H. J. McSorLeY, C. S. P., Luthers Lehre vom unfreien Willen nach seiner Hauptschrift De Servo Arbitrio im Lichte der biblischen und kirchlichen Tradition, München 1967. 
del Génesis, será preciso que tanto los católicos como los protestantes se vayan deshaciendo con prudencia de todos aquellos aspectos históricos del pecado original que no puedan ser armonizados con la nueva situación, aunque hayan sido aceptados y ampliamente elaborados hace siglos por los grandes corifeos del cristianismo y por los iniciadores de la Reforma.

Ciertamente nunca podrá satisfacernos una explicación meramente filosófica, por más existencial que aparezca, y la psicologa más profunda sólo logrará ayudarnos a constatar la falta de orden y armonía en nuestro mundo interior; pero, sin la luz de la revelación, la situación actual de la humanidad seguirá siendo un misterio inexplicable, o mejor, un absurdo sin remedio.

Tanto la teología católica como la protestante deberán buscar un camino en el que resalte el aspecto individual y libre de nuestra situación pecaminosa, para que la doctrina del pecado original sea fidedigna a la sensibilidad del hombre moderno. Sin embargo, creemos que la situación del mundo presente exige al protestantismo clásico una revisión mucho más profunda de sus doctrinas, que a la teología católica. Esa negación radical del libre albedrío en el orden religioso, defendida por Lutero y, con diversos matices, por los demás reformadores ; esa corrupción intrínseca de la naturaleza humana en el plano psicológico-religioso, y el consiguiente determinismo salvífico o predestinacionismo, todo ese pesimismo profundo e incurable en esta vida, no podrá en modo alguno satisfacer el sentido de responsabilidad individual del hombre moderno. Del mismo modo, esa mengua de la razón-prostituta (Hure) en el orden trascendental y religioso, que Lutero proclama con tanta viveza ${ }^{59}$, así como la maldad o maldición inmersa por el pecado en todas las criaturas que nos rodean ${ }^{60}$, cierran el paso tanto a la teología de las religiones no oristianas y a la teología de las realidades terrenas, canonizadas por el Vaticano II, como a la filosofía del derecho, tan importante en la civilización moderna ${ }^{61}$. Además, en la teología protestante clásica

\footnotetext{
59 Lutero la llama "esposa del diablo" y "la más grande prostituta del diablo" (die höchste Hure, die der Teufel hat), etc. Cfr. Predigten des Jahres (1526), W., 20, 230.

60 Nec dubito quin ante peccatum aura purior et salubrior, aqua foecundior, imo quoque solis lumen pulchrius et clarius fuerit, ita ut tota creatura in omni parte nos admoneat maledictionis per peccatum implicitae (In I Lib. Mose, W., 42, 153); ib., W., 42, 48.

61 Cfr. A. REBER, Katolische und protestantische Rechtsbegrïndung heute, Frankfurt a. Main 1962.
} 
no hay cabida posible para un diálogo con el humanismo moderno o, al menos, tiene que resultarle mucho más difícil que a la teología católica. El mismo filósofo comunista francés, Roger Garaudy, refiriéndose a la doctrina de Calvino sobre la predestinación absoluta (decretum horribile), que lleva la postura de Lutero hasta sus últimas consecuencias, no duda en afirmar: "La predestinación de Calvino dio lugar en las almas a una angustia más sombría que la necesidad de los átomos de Epicuro, y tradujo la confusión de las almas en el caos del feudalismo en descomposición" ${ }^{62}$. Aunque un comunista no pueda comprender lo que significa para un cristiano la fe en los méritos de Cristo, sin embargo no le falta toda la razón al constatar la anulación total del individuo ante su propio destino final. Por eso, la lucha de Lutero y de los primeros reformadores contra el neopelagianismo de algunos nominalistas ${ }^{63}$, debería librarse de ese excesivo pesimismo antropológico y de su determinismo salvífico a ultranza. Aunque las comunidades de la Reforma sigan en general fieles a la doctrina primitiva de sus fundadores, ya sabemos que hay varios teólogos que siguen hoy día su propio camino; pero también es cierto que muchos teólogos protestantes, de signo liberal, caen en el extremismo opuesto de reducir toda la treligión a una especie de filosofía, inmanentista o existencialista, que desvirtúa por completo el mensaje cristiano. Lo difícil está en conservar el equilibrio justo entre las verdades fundamentales del cristianismo y la nueva mentalidad del mundo.

Por otra parte, la teología católica deberá conservar a toda costa la realidad del pecado y de la redención, si no quiere caer también en un optimismo de tipo naturalista que prive a Cristo y a su Iglesia de su razón de ser-en-el-mundo. El equilibrio del Vaticano II, especialmente en su Constitución Gaudium et Spes, es el mejor antídoto de las posibles desviaciones en este sentido.

2. Tanto San Pablo como San Agustín nos describen el pecado de origen y sus secuelas impulsados por la revelación y por la propia expe-

62 R. GaRAudy, ¿Qué es la moral marxista?, Buenos Aires 1964, 27.

63 P. Vignaux, Luther commentateur des sentences, Paris 1935; B. HaEgGI,UND, Theologie und Philosophie bei Luther und in der occamistischen Tradition: Luthers Stellung zu der Theorie der doppelten Wahrheit, Lund 1955; H. A. OBERMANN, The Harvest of Medieval Theology, Harvard University 1963; L. BouYER, La spiritualité orthodoxe et la spiritualité protestante et anglicane, Paris 1965, 91-94; K. Algermissen, Iglesia Católica y Confesiones Cristianas, Madrid 1964, $767-772$. 
riencia interna y externa de la lucha cruel entre la carne y el espíritu. En parte es éste un impulso existencial, que Lutero adoptó también sin reservas, pero sin la perspectiva bíblica y teológica de los primeros siglos del cristianismo, según vimos antes. Por eso, su justificación forense o puramente extrínseca choca contra la teología bautismal de San Pablo y contra la doctrina agustiniana de la imagen divina del hombre y de la eficacia de los sacramentos. Su escatología se convierte así en una pura esperanza de la vida futura, sin un comienzo ya verdaderamente real en esta vida ${ }^{64}$. Es una concepción en exceso jurídica de la antropología cristiana, que volverá a brotar de un modo parecido en el jansenismo posterior.

Pero también hemos de notar que la teología católica, a partir del concilio de Trento, insiste casi exclusivamente en la renovación ontológica o metánoia interior del cristiano por la gracia santificante y las virtudes infusas. Es cierto que la liturgia y, en general, los escritos de ascética y mística conservan en toda su pureza la conciencia del pecado y la confianza sentida y constante en los méritos de Cristo. Sin embargo, con esa insistencia de la teología católica en la renovación ontológica del cristiano por la justificación quedó bastante oscurecida la parte de verdad que contenía la doctrina de los Reformadores, y un tanto empobrecida la doctrina de toda la tradición cristiana: la justificación es ciertamente una renovación ontológica interior, que se realiza mediante la reforma o restauración de nuestra imagen y semejanza divina, fundamento de toda renovación individual y eclesiástica, pero en los adultos esta renovación no se realiza sin la confianza o fe fiducial en los méritos de Cristo, único Mediador nuestro. Esta es la única actitud posible del cristiano ante el misterio de su redención por Cristo, ya que, según nos enseña el mismo concilio de Trento, nadie, a no ser por una revelación especial, puede saber con certeza si es digno de amor o de odio. Por eso Seripando, prior general de los agustinos, y sus seguidores pedían con tanta insistencia que esa confianza en Cristo fuera también incluída en el "decreto tridentino de la justificación (duplex iustitia). El Concilio no rechazó esa doctrina, si bien no juzgó oportuno inserirla en el de-

64 In I Lib. Mose, W., 42, 48. "Ut haec vita cognoscatur non esse iustitia sed iusificatio, non sanitas sed sanatio, non finis sed phase domini, non terra sed migratio, et prorsus continua purgatio peceati et transitus de virtute in virtutem... A.t talis transitus certe manifestat, reliquum esse semper peccatum, a quo recedamus et ad maiorem iustitiam propinquemus" (Assertio omnium articulorum..., W., 7, 107). 
creto. La calificación de duplex iustitia que le dio Seripando, por ese cierto sabor luterano de la dialéctica de los contrarios, hizo que la teología posterior enturbiara su verdadero sentido. En realidad, esa doctrina implicaba al mismo tiempo la renovación ontológica interior y la actitud de confianza total en los méritos de Cristo, como un todo indivisible en la justificación del adulto. Y es preciso que esos dos elementos aparezcan inseparables, si no queremos que nuestros razonamientos teológicos resulten truncados y en pleno contraste con la realidad de nuestra vida cristiana ${ }^{65}$. Por mi parte, creo que todo verdadero cristiano aceptará plenamente la verdad de la última frase que escribió Lutero antes de su muerte: "Somos mendigos, esto es verdad" ${ }^{66}$. Todos somos mendigos de Dios; mendigos y enfermos, por las heridas del pecado, que Cristo, el Medicus humilis de que habla San Agustín, vino a curar poco a poco en esta vida hasta que nos conceda la sanación total en la vida futura. Todos los testamentos de los Santos se hacen eco de esta postura reaimente cristiana, y sin la confianza en su amado Redentor se sentirían desvalidos y con las manos vacías ante el tribunal del Juez Supremo. Se impone, pues, de nuevo conservar en todo el equilibrio del misterio cristiano, sin querer enfrentar nunca al hombre con su Creador y Redentor, pero también sin aniquilar por completo su actividad en la historia de salvación, que cada uno habrá de ir escribiendo con su propia mano guiado por la mano paternal de Dios.

3. El teólogo luterano Iulius Gross se ha empeñado últimamente en atribuir a San Agustín la invención antibíblica del pecado original hereditario (Erbsünde), pasando por alto la doctrina de San Pablo y de la tradición patrística anterior al Hiponense ${ }^{67}$. Es la misma acusación gratuita que le hacía ya a San Agustín el duro y astuto pelagiano Julián

65 Cfr. A. Turrado, "Fe en Cristo y fe en la unidad de los cristianos": Revista Agustiniana de Espiritualidad 9 (1968) 5-16; ver pp. 9-10); P. PAs, "La doctrine de la double justice au Concile de Trente": Ephemerides Theol. Lov. 30 (1954) 5-53; D. GuTiérRez, O. S. A., "Al margen de libros y artículos acerca de Lutero": La Cuidad de Dios 169 (1956) 609-637; ver pp. 627-632; A. Trape, O. S. A., "Scuola teologica e spiritualità nell'Ordine Agostiniano": "Sanctus Augustinus vitae spiritualis Magister", II (Roma 1959) 5-75; ver pp. 50-59.

66 J. LoRTz, Historia de la Reforma, I, p. 455.

67 J. GRoss, Entstehungsgeschichte des Erbsündendogmas. Von der Bibel bis Augustinus, München-Basel 1960, p. 386. 
de Eclana: "Quasi ego prior vel crediderim vel esse disputaverim originale peccatum" ${ }^{68}$.

Varios teólogos católicos han salido ya al encuentro de tan infundadas afirmaciones, tratando de distinguir entre lo esencial de la tradición cristiana sobre el pecado original y ciertos progresos nacidos al calor de la polémica antipelagiana de San Agustín ${ }^{69}$. Todo esto debe ponernos en guardia contra toda posible exageración. Porque esos teólogos católicos y protestantes, que tienden a desvirtuar casi por completo la tragedia del pecado original, si desean seguir siendo cristianos, deberán conservar al menos los elementos fundamentales de la doctrina agustiniana, que es la doctrina tradicional de todo el cristianismo, es decir: el hecho de la universalidad del pecado, y la necesidad de la redención de Cristo. Sin esto, la desmitologización del dogma, al estilo de R. Bultmann, acabará por no dejar intacta ni una sola de las verdades cristianas.

Por lo demás, la evolución del dogma debe seguir con prudencia su camino. San Agustín puede servirnos en esto de modelo; él, que fue uno de los más ardientes buscadores de la verdad, y que no dudó en confesar la imposibilidad de llegar a poseerla plenamente en esta vida: "Non arbitror in hac vita in cuiusquam mente posse compleri" ${ }^{70}$. También el dogma del pecado original deberá ser expuesto en el lenguaje accesible a la mentalidad del hombre moderno, pero sin desvirtuarlo. La primera formulación oficial en los nueve cánones del concilio de Cartago (418), y la doctrina de San Agustín no pueden ser relegadas sin más al olvido ${ }^{71}$. Sería un verdadero suicidio sin remedio.

Lutero no cesa de ensalzar el magisterio universal de San Agustín. Ya al final de su vida, propone el ejemplo de la oración de Santa Mónica como modelo de la verdadera oración cristiana. Por su fe y confianza en Dios, no sólo obtuvo la conversión de su hijo, sino su dedicación 44,843 .

68 Op. imperf. c. Iul., II, 104, PL. 45, 1.184; Contra Iul., VI, 12, 39, PL.

69 Ch. Boyer, Le péché originel, en "Théologie du péché", Tournai 1960, 243-291; A. VANNESTE, "L'histoire du dogme du péché originel": Ephemerides Theol. Lov. 38 (1962) 895-903; F.-J. ThONNARD, "Prétendues contradictions dans la doctrine de saint Augustin sur le péché originel": Revue des Études Augustin. 9 (1963) 383-387; 10 (1964) 370-374; A. SAGE, "Péché originel. Naissance d'un dogme": Ib., 13 (1967) 211-248; Id., "Le pécné originel dans la pensée de saint Augustin, de 412 à $430 "$ : $I b ., 15$ (1969) 75-112.

70 In Io. tr. 86, 4, PL. 35, 1876.

71 Cfr. A. SAGE, "Le péché originel dans la pensée de saint Augustin, de 412 à $430 "$ : Ib., 15 (1969), p. 112. 
total al estudio de la ciencia de Dios, de tal modo que llegó a ser luz y guía perenne en la Iglesia: "non solum convertitur Augustinus et baptizatur, sed totum se ad studium Theologiae confert, et fit talis Doctor, qui usque in hunc diem in Ecclesia lucet, eamque docet et instituit" 72 . Sería lamentable tener que constatar la veracidad de esa afirmación un tanto desconcertante, que comienza a oirse ya en ciertos ambientes: "A este paso va a resultar que muchos protestantes son más católicos que muchos católicosl".

P. Argimiro Turrado, O. S. A.

72 In I Lib. Mose, W., 42, 662. 